LBNL-47889

\title{
PRELIMINARY ENGINEERING ANALYSIS FOR CLOTHES WASHERS
}

October 1996

\author{
Peter J. Biermayer \\ LAWRENCE BERKELEY NATIONAL LABORATORY \\ Energy \& Environment Division \\ Berkeley, CA 94720
}

Prepared for

U.S. DEPARTMENT OF ENERGY

Office of Codes and Standards

\footnotetext{
This work was supported by the Assistant Secretary for Energy Efficiency and Renewable Energy, Office of Building Technology, State and Community Programs, Office of Codes and Standards, of the U.S. Department of Energy under Contract No. DE-AC03-76SF00098.
} 
TABLE OF CONTENTS

\section{PRELIMINARY ENGINEERING ANALYSIS FOR CLOTHES WASHERS}

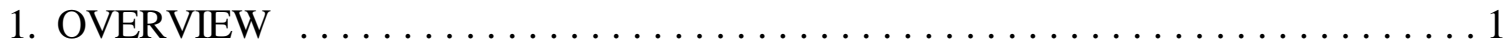

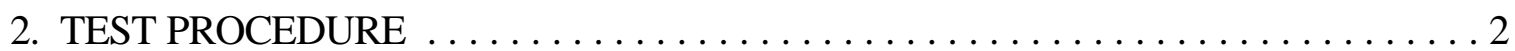

3. ENERGY-USE AND COST ANALYSIS $\ldots \ldots \ldots \ldots \ldots \ldots \ldots \ldots \ldots \ldots \ldots$

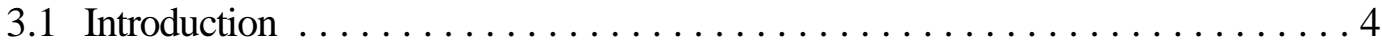

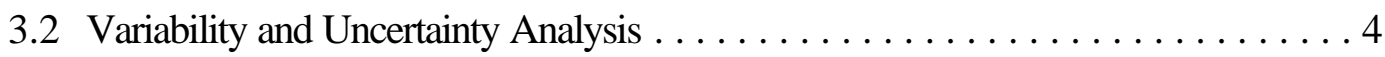

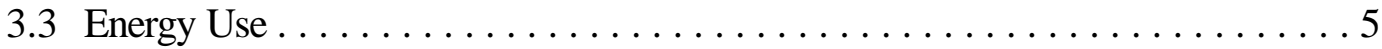

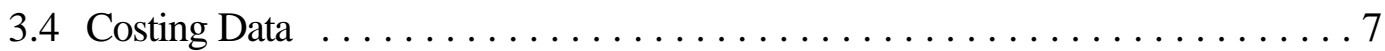

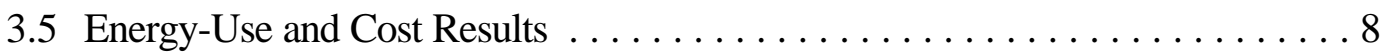

4. MAXIMUM TECHNOLOGICALLY FEASIBLE DESIGN $\ldots \ldots \ldots \ldots \ldots \ldots 12$

APPENDIX A. DISAGGREGATED MANUFACTURER COST DATA $\ldots \ldots \ldots$ A-1 APPENDIX B. ADJUSTMENTS TO AHAM DATA $\ldots \ldots \ldots \ldots \ldots \ldots \ldots \ldots$ B-1

B.1 Adjustments due to Statistical Variations $\ldots \ldots \ldots \ldots \ldots \ldots \ldots \ldots \ldots$ B-1

B.2 Adjustments due to Normalization ...................... B-1

B.3 Adjustments due to Test Procedure Changes .................. B-2 APPENDIX C. RAW DATA PROVIDED BY AHAM $\ldots \ldots \ldots \ldots \ldots \ldots \ldots$ C- 1 APPENDIX D. DRYER EFFICIENCY FUEL CORRECTION DERIVATION ..... D-1 APPENDIX E. CALCULATIONS FOR IMPROVED WATER EXTRACTION

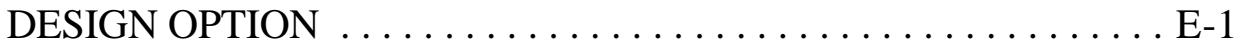
APPENDIX F. CLOTHES CONTAINER CAPACITY $\ldots \ldots \ldots \ldots \ldots \ldots \ldots$ F-1

\section{LIST OF TABLES}

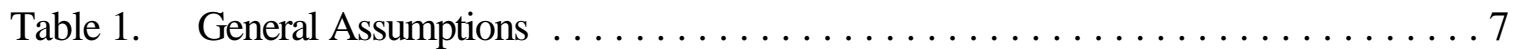

Table 2. Standard Clothes Washer: Cost, Energy-Use, and Water-Use Data . . . . . . . 9

Table A.1 Disaggregated Cost of Efficiency Improvements for Standard

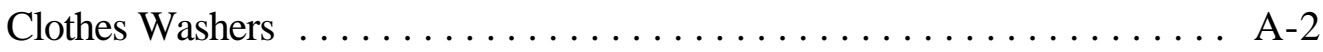

Table B.1 Temperature Use Factors for Proposed AHAM and Future DOE Test Procedures . . . . . . . . . . . . . . . . . . . . . . .

Table C.1 Raw Data Provided by AHAM and Used in the Engineering Analysis . . . . C C-2 Table C.2 AHAM Confidence Level and Limiting Performance Factor Data ........ C-4

Table D.1 Dryer Energy at 70\% Initial Moisture Content $\ldots \ldots \ldots \ldots \ldots \ldots \ldots$ D-1

\section{LIST OF FIGURES}

Figure 1. Manufacturer Cost vs. Modified Energy Factor .................. 11 


\section{Clothes Washer Preliminary Engineering Analysis}

\section{OVERVIEW}

The Engineering Analysis provides information on efficiencies, manufacturer costs, and other characteristics of the appliance class being analyzed. For clothes washers, there are two classes: standard and compact. Since data were not available to analyze the compact class, only standard clothes washers were analyzed in this report. For this analysis, individual design options were combined and ordered in a manner that resulted in the lowest cumulative cost/savings ratio. The cost/savings ratio is the increase in manufacturer cost for a design option divided by the reduction in operating costs due to fuel and water savings.

A significant amount of information gathering and analysis was conducted before the new interpretive rule process approach was implemented, therefore, some preliminary results are presented here as a point for discussion. The methodologies used in the final engineering analysis report will be addressed after consultation with stakeholders. Uncertainty and variability of data must also be addressed before the engineering analysis is completed. Other input from stakeholders is also encouraged for the final engineering analysis report. Alternative approaches can be explored or present approaches can be modified and refined. Also open for discussion is what variables or uncertainties need to be analyzed.

\section{Baseline Units}

A baseline unit is the starting point for analyzing design options for improving energy efficiency. In this report, the baseline unit represents a typical model with an energy efficiency no lower than the minimum required by the amended National Appliance Energy Conservation Act (NAECA) (Energy Factor $\geq 1.18 \mathrm{ft}^{3} / \mathrm{kWh}$ ). The baseline energy use is based on the shipmentweighted average of major American manufacturers' models.

\section{Design Options}

Design options that are presently commercially available or that are in prototypes were established in Draft Report on Design Options for Clothes Washers [1]. This report also discussed design options which were screened out from further analysis based on provisions detailed in the Department of Energy's Interpretive Rule [2]. Analysis of economic criteria will be found in a future report.

\section{Maximum Technologically Feasible Designs}

A maximum technologically feasible design option consisting of a combination of individual design options was identified. This option, or combination of options, results in the highest energy 
efficiency. The maximum technologically feasible efficiency level must be either commercially feasible or available as a working prototype.

\section{Efficiency Calculation}

The efficiency levels corresponding to various design options were determined from manufacturer data and from engineering calculations.

\section{Cost Estimates}

Estimates of manufacturer cost were received in response to a questionnaire sent out by Lawrence Berkeley National Laboratory (LBNL) to the Association of Home Appliance Manufacturers (AHAM). Appendix A contains detailed incremental cost data disaggregated into labor, purchased parts and materials, shipping/packaging, and investment. The sum of individual design option costs were used for design options combined in this analysis (i.e., those not previously combined by AHAM or manufacturers).

\section{Cost-Efficiency Relationships}

The results of the Engineering Analysis are summarized in cost-efficiency relationships which show the efficiency and manufacturer cost of the design options.

\section{Outputs from the Engineering Analysis}

For each combination of design options considered in the analysis, the following are provided:

- $\quad$ energy efficiency (expressed as a Modified Energy Factor $^{1}$ and unit energy consumption);

- $\quad$ increased variable and fixed costs for manufacturers;

- $\quad$ annual energy consumption per unit (based on DOE test procedures);

- $\quad$ the relationship between cost and efficiency; and

- $\quad$ change in water consumption.

\section{TEST PROCEDURE}

Since this analysis is based on a future Department of Energy (DOE) test procedure, it is important to discuss proposed changes to the test procedure. The Department has proposed two new

\footnotetext{
${ }^{1}$ The Modified Energy Factor is a measure of energy efficiency derived from the future DOE test procedure for each product type.
} 
clothes washer test procedures in a Supplemental Notice of Proposed Rulemaking; Appendices "J" and "J1" [3]. In this report, the two new versions of the test procedure "J" and "J1" will be referred to as the "proposed" and "future" test procedure, respectively. The proposed (Appendix J) test procedure will take effect shortly after being completed and published in the Federal Register as a final rule. The "future" (Appendix J1) test procedure will take effect only when a new clothes washer standard is enacted. The Engineering Analysis presented in this report is based on the future (Appendix J1) test procedure.

The test procedure used in analyzing design options is important not only because of differences in the magnitude of energy savings predicted but also because it has the potential to change the ranking of design options. For example, the energy savings due to a thermostatically controlled mixing valve (TCMV) are dependent on the hot water temperature set point of the water heater.

\section{Existing test procedure}

The existing test procedure specifies $140^{\circ} \mathrm{F}$ inlet water and 416 clothes washer cycles per year [4]. The existing test procedure is carried out without a cloth test load for vertical axis clothes washers.

\section{Proposed test procedure (Appendix J)}

The Appendix J test procedure will not alter the existing energy factor of any clothes washer that is required to meet the current efficiency standard, except for clothes washers with temperature selections which are locked out of the normal cycles [5]. Test procedure changes include 1) a clothes washer use of 392 cycles per year, 2) clarification of wash/rinse temperatures to avoid ambiguity, 3) specification of agitation and spin speed settings, 4) addition of water heating clothes washer capability, and 5) new provisions to account for an automatic fill control feature. In addition, the following informational quantities are defined: 1) total (both hot and cold) water consumption, 2) remaining moisture content (RMC) in the test load after the final spin cycle, and 3) a calculated modified energy factor (MEF). The MEF will include the energy needed to dry clothes in a dryer after a final washer spin cycle . Determining the MEF will not be mandatory.

\section{Future test procedure (Appendix J1)}

This DOE clothes washer test procedure has been proposed in order to more accurately reflect actual energy usage and adapt to the continuing changes in clothes washer design. This test procedure will make some of the informational changes in the Appendix J test procedure mandatory [6]. Among the changes in the test procedure will be 1) new temperature use factors (TUFs), 2) lowering of the inlet hot water temperature from the existing $140^{\circ} \mathrm{F}$ to $135^{\circ} \mathrm{F}, 3$ ) a water temperature rise change from $90^{\circ} \mathrm{F}$ to $75^{\circ} \mathrm{F}$ and 4) provisions to account for adaptive control and automatic fill control. In addition, clothes washer test loads will depend on washer capacity, remaining moisture content after a final spin cycle will be taken into account, and the MEF will replace the current 
energy factor (EF) for standard compliance. (Reporting of the energy factor (EF) will be kept for voluntary programs.) The above changes should result in a more accurate prediction of actual clothes washer and clothes dryer energy use.

\section{ENERGY-USE AND COST ANALYSIS}

\subsection{Introduction}

A cost and efficiency questionnaire sent to AHAM was responded to by five AHAM member manufacturers, however not every manufacturer provided energy-use and cost data for each design option considered. AHAM submitted energy usage data based on both the existing DOE test procedure and a proposed ${ }^{2}$ AHAM test procedure. Differences between the proposed AHAM and future DOE test procedures are discussed in Appendix B.

After LBNL performed an initial engineering analysis, additional information was requested on combinations of design options, particularly for design options that could be used on both vertical and horizontal axis washers. Additional data were desired because inherent design differences between vertical and horizontal axis washers could result in different incremental costs and energy savings for a given design option. Certain synergies in cost and efficiencies could also result from combining some design options. The analysis performed was divided into two basic stages; Phase I and Phase II. Phase I is the analysis of the responses from the initial questionnaire and Phase II includes responses from additional data requests (e.g., combined design options and further disaggregated design options). Data from both Phase I and Phase II were used in the final analysis. Where possible, data submitted from Phase II were used. Data from Phase I were used when needed to analyze design options not covered in the Phase II data submittal. The raw data supplied by AHAM are provided in Appendix C.

\subsection{Variability and Uncertainty Analysis}

Because of large differences (in some instances) in cost and energy use data provided by manufacturers it is important to analyze the effect of variability and uncertainty in the data used in the engineering analysis.

Variability refers to differences in input values, for example, costs for a design option. Even if in some cases the manufacturers know how much a design option would cost them to implement, these costs may be different among manufacturers. Similarly for fuel costs, although current costs for fuel are known, fuel prices vary among electric or gas utilities. Uncertainty is a measure of how a data value may vary if the exact value is unknown. For example, although all manufacturers might agree on the probable cost of a design option, the exact cost may be unknown. Parameters with

\footnotetext{
${ }^{2}$ In this report "proposed AHAM test procedure" refers to an early version of the AHAM test procedure which was used by manufacturers to submit data.
} 
variability and uncertainty applicable to the engineering analysis include manufacturer cost, fuel price, usage in cycles per year, predicted energy savings, and water price.

To avoid releasing confidential information, AHAM submitted manufacturing costs and energy usage data as shipment weighted averages. Along with the actual values, information on the standard deviation of the data was also provided (see Appendix C). How these data should be used and whether or not an alternative metric (such as a range of submitted values) can be provided is open for discussion. Differences in how fixed and variable costs were submitted by AHAM may also be discussed (see Appendix A).

Data were also provided on confidence factors for: cost and investment data, mass production success, and marketing success. Of these, cost and investment data are directly applicable to the engineering analysis. Stakeholder input is requested in how to explictly utilize these confidence factors in the analyses.

One approach to account for variability and uncertainty would be to statistically determine which input variables have a significant impact on the output of the engineering analysis. This approach could similarly be used to measure the effect of input paramenter variability on the metrics used in determining what the appliance standard should be, if one is promulgated. This statistical approach could also be used to determine the frequency of occurrence of life-cycle cost reduction or of payback being greater than a specific value. Methods such as the one mentioned above have been used on other products to determine the affect of variability and uncertainty on consumer impacts (i.e., payback and life-cycle cost). However, these metrics are currently not the subject of the engineering analysis. In previous rulemakings, sensitivity analyses have been performed by assuming a high and low value for various data inputs (e.g., electricity price). Sensitivity analyses may be discussed in the future when doing consumer and national impact analyses.

\subsection{Energy-Use}

Adjustments had to be made to the data submitted by AHAM because 1) not all manufacturers provided data for all design options and 2) differences in the proposed AHAM and future (Appendix J1) DOE test procedures. Test procedure changes included adjustments in: 1) inlet hot water temperature, 2) TUFs, and 3) dryer usage factor (DUFs). Appendix B details the adjustments made to the AHAM data.

Cost/savings ratios were calculated for all individual design options (referenced to the baseline). As depicted in Eq. 1, the cost/savings ratio is the increase in manufacturer cost for a design option divided by the reduction in operating costs due to fuel and water savings. 


$$
\text { Cost } / \text { Savings Ratio }=\frac{\Delta \text { Cost }_{\text {mfg }}}{\Delta \text { Cost }_{\text {operating }}}
$$

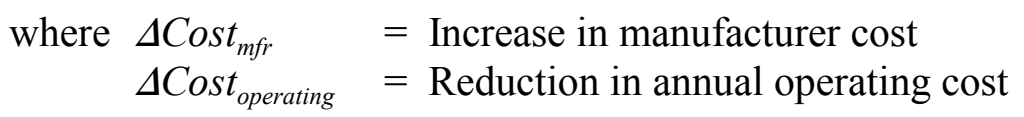

Those design options with very high cost/savings ratios were identified and not combined with other design options in order to reduce the total number of combinations. Those not combined were: 1) added insulation, 2) increased motor efficiency, 3) direct drive motor, and 4) advanced controls.

Individual design options were also combined where possible to determine if greater possible energy savings were feasible. However, in some instances design options were not considered compatible with each other. For example, tighter tub tolerance was not combined with lower RMC options or horizontal axis designs because of greater possible tub deflection at higher spin speeds (which is one method of achieving lower RMCs). Improved fill control and automatic fill control were considered two distinct methods of achieving the same goal and were, therefore, not combined with each other.

Cost/savings ratios were calculated for various combinations of gas and electric water heaters and clothes dryers. Generally, design options were ranked and combined by lowest cumulative cost/savings ratio. Operating costs used in determining the savings portion of the cost/savings ratio were based on a weighted average of both gas and electric water heaters and dryers. The weighted average operating costs were derived by first calculating the cost in dollars per year required for heating water and drying clothes for each fuel type separately. Then average dollars per year were calculated for pairings of gas and electric water heaters, with similar averages calculated for combinations of gas and electric dryers. An average cost in dollars per year for water heating and clothes drying is then the sum of the water heater average and the clothes dryer average.

In some instances, other considerations took precedence when ranking design options. An example involves the horizontal axis and lower RMC designs where the RMC design option should precede the horizontal axis design option because it has a lower cost/savings ratio. However, since a horizontal axis machine may affect the cost and performance of adding on a RMC feature, horizontal axis was placed ahead of it. With regard to combined design options submitted by AHAM (some were submitted precombined in Phase II), if they had a lower cost/savings ratio than one of its single design option components, then the single (uncombined) design option was not used.

For some cases, it was not technically correct to simply add individual energy or water savings to determine the energy and water saved due to combined options. The following procedure was used in determining hot water energy for the improved fill control, automatic fill control (auto- 
fill), and TCMV design options. First, the energy for the individual design option was determined. Next, the ratio of the individual design option's energy use to the baseline's energy use was calculated. This ratio was then used to multiply the energy use of the immediately preceding design option to arrive at the lower energy use for the combined design option. Similarly the above method was used to determine the reduced water use for improved fill control and auto-fill control design options.

\section{General Assumptions}

Table 1 shows the assumptions made in order to carry out the energy-use and energy cost calculations.

Table 1. General Assumptions

\begin{tabular}{lcl}
\hline Parameter & Value & Source \\
\hline Baseline Clothes Container Volume & 2.9 cubic feet & AHAM [7] \\
Cycles per Year & 392 & Future DOE test procedure [8] \\
Electricity Price & $0.083594 \$ / \mathrm{kWh}$ & AEO 1996 [9] \\
Natural Gas Price & $6.075 \$ / \mathrm{MBtu}$ & AEO 1996 [10] \\
Electricity Price Multiplier & 0.90 & LBNL \\
Natural Gas Price Multiplier & 1.01 & LBNL \\
Water and Sewage Cost & $2.84 \$ / \mathrm{kgal}$. & Seattle Water [11] \\
Water Heater Efficiency, Electricity & $100 \%$ & Existing DOE Test Procedure [12] \\
Water Heater Efficiency, Gas & $75 \%$ & Existing DOE Test Procedure [13] \\
Fraction Electric Water Heaters & 0.45 & AHAM [14] \\
Fraction Gas Water Heaters & 0.55 & AHAM [15] \\
Fraction Electric Clothes Dryers & 0.75 & AHAM [16] \\
Fraction Gas Clothes Dryers & 0.25 & AHAM [17] \\
Initial Remaining Moisture Content & $62 \%$ & AHAM [18] \\
Dryer Usage Factor (DUF) & 0.84 & Future DOE Test Procedure [19] \\
Drying Efficiency of Clothes Dryer & $0.5 \mathrm{kWh} / \mathrm{lb}$. & Future DOE Test Procedure [20] \\
Gas Dryer Correction Factor (GCF) & 1.12 & See Appendix D \\
Percentage of Time RMC Option Used & $75 \%$ & See Appendix E \\
\hline
\end{tabular}

It was assumed for this analysis that the clothes load was not a function of clothes container volume. Appendix F discusses this assumption.

\subsection{Costing Data}

All incremental manufacturer cost data are based on AHAM-supplied data. Disaggregated costs are shown in Appendices A and C. 


\subsection{Energy-Use and Cost Results}

The energy use and cost of design options are shown in Table 2.

The analysis was organized to allow maximum flexibility in selecting alternative efficiency levels for further study. Typically, an engineering analysis is based on arranging combinations of design options by lowest cumulative cost/savings ratio. Although this was the basic approach used, where this would limit choices of design options, additional design paths were created. For example, horizontal axis with recirculation was branched off of the basic horizontal axis path (itself a branch) to enable analysis of the different RMC options with horizontal axis without recirculation. Table 2 separates the design options into five categories $(\mathrm{a}, \mathrm{b}, \mathrm{c}, \mathrm{d}, \mathrm{e})$. They are:

- $\quad$ Category a: Vertical axis with RMC design options;

- $\quad$ Category b: Horizontal axis;

- $\quad$ Category c: Horizontal axis with recirculation;

- Category d: Vertical axis with tighter tub tolerance. This was separated from "category a" on the assumption that tighter tub tolerance is not compatible with lower RMC achieved by increasing the spin speed; and

- $\quad$ Category e: Options not analyzed in combination with other design options.

The cost/efficiency relationship of the design options in Table 2 is shown graphically in Figure 1. 


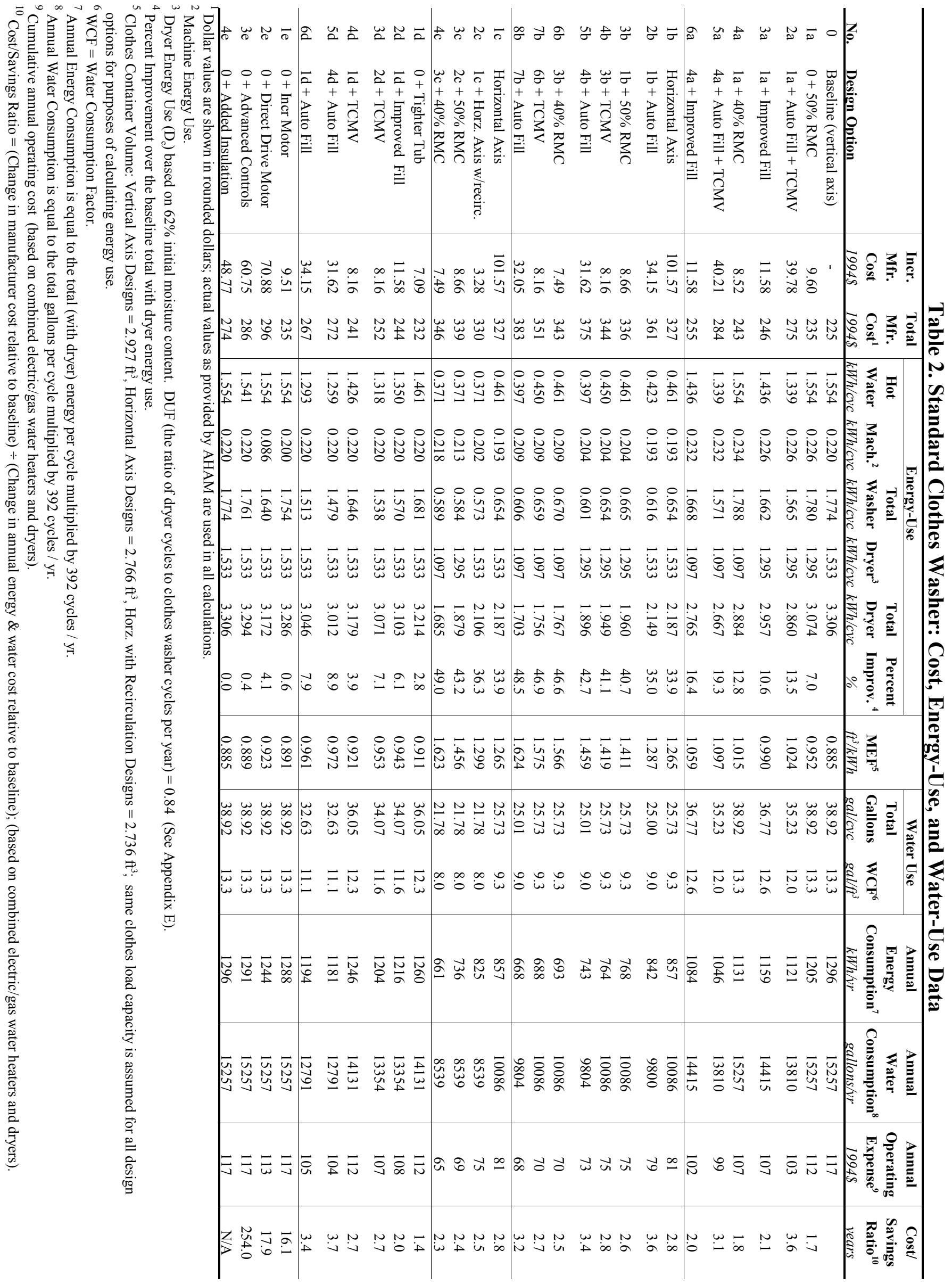


Headings used in Table 2 are described below.

Incremental Manufacturer Cost. This is the cost that would be incurred if the design option were required to meet a minimum efficiency standard and would therefore be mass-produced approximately at the same level as current production levels. For this reason some prices for models, such as horizontal axis washers, would be substantially lower than those currently on the market due to economies of scale. These values are based on data provided by AHAM.

Total Manufacturer Cost. This cost is determined by adding a design option incremental cost to the total manufacturer cost of the previous design option.

Hot Water Energy Use. This is the energy content of the hot water supplied by the water heater external to the washing machine.

Machine Energy Use. This is the electrical energy input to the washer during a washer test cycle.

Total Washer Energy Use. This is the sum of the hot water and machine energy use.

Dryer Energy Use. This is the amount of energy needed to complete the drying of the test load in a clothes dryer after the final spin cycle.

Total Energy Use with Dryer. This is the sum of hot water energy, machine energy, and dryer energy use.

Percent Improvement. This is the percent reduction in washer energy use (including dryer energy) over the baseline case.

Modified Energy Factor (MEF). This is the ratio of washer volume in cubic feet to total energy where the total energy includes the dryer (moisture removal) energy. MEF differs from EF in that the energy needed to dry clothes, after a spin cycle, is added to the total energy use. MEF is given in units of cubic feet per $\mathrm{kWh}$ per cycle. The following equation demonstrates how MEF is calculated.

$$
M E F=\frac{\text { Clothes Container Volume }}{\text { Hot Water Energy }+ \text { Mechanical Energy }+ \text { Dryer Energy }}
$$

Total Gallons. This is the total amount of water used per cycle, both hot and cold.

Water Consumption Factor (WCF). This is the total gallons of water used in a test cycle divided by the clothes container volume in cubic feet. 
Annual Energy Consumption. This is total washer and dryer energy usage in $\mathrm{kWh}$ for an entire year based on 392 clothes washer cycles per year.

Annual Water Consumption. This is the total water consumption in gallons (both hot and cold) in an entire year based on 392 clothes washer cycles per year.

Annual Operating Expense. This is cost in fuel and water to run a washing machine for one year plus the cost to dry the clothes as well. The dollar amount is reported in 1994 dollars.

Cost/Savings Ratio. This ratio describes the increase in manufacturer cost for one or more design options relative to the savings in annual operating expense.

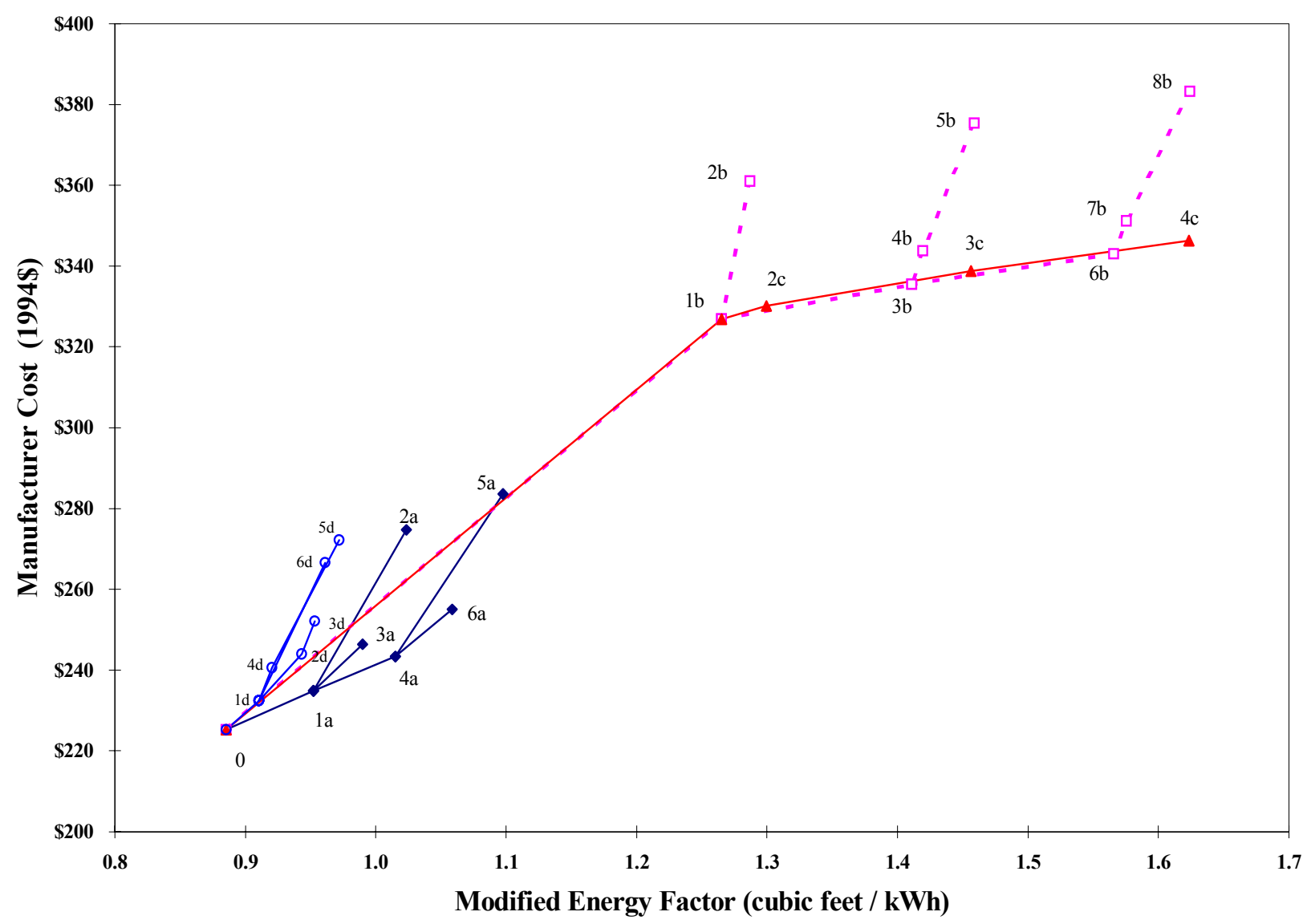

Figure 1. Manufacturer Cost vs. Modified Energy Factor 


\section{MAXIMUM TECHNOLOGICALLY FEASIBLE DESIGN}

The maximum technological feasible design based on energy use per cycle is a horizontal axis washer with recirculation and a RMC of $40 \%$. This design would reduce total laundry energy consumption (for both washing and drying) by $49.0 \%$ and washing energy alone by $66.8 \%$. The MEF for this design is 1.62 . 


\section{REFERENCES}

1. U.S. Department of Energy (DOE). 1996a. Draft Report on Design Options for Clothes Washers, October 1996.

2. U.S. DOE. 1996b. Procedures, Interpretations and Policies for Consideration of New or Revised Energy Conservation Standards for Consumer Products; Final Rule. Federal Register Vol. 61, No. 136, Appendix A to Subpart C of Part 430 -- July 15, 1996.

3. U.S. DOE. 1996c. Energy Conservation Program for Consumer Products: Test Procedure for Clothes Washers and Reporting Requirement for Clothes Washers, Clothes Dryers, and Dishwashers. (61 Federal Register 17589, April 22, 1996.), 10CFR, Part 430, Appendices $\mathrm{J} \& \mathrm{~J} 1$, Docket No. EE-RM-94-230A.

4. U.S. Office of the Federal Register. 1994. Code of Federal Regulations, Title 10, Appendix $\mathrm{J}$ to Subpart B or Part 430 -- Uniform Test Method for Measuring the Energy Consumption of Automatic and Semi-automatic Clothes Washers, January 1, 1994.

5. U.S. Office of the Federal Register. 1995. Code of Federal Regulations, Title 10, Part 430, Vol. 60, No. 56, p. 15335, Proposed Rules, March 23, 1995.

6. U.S. DOE. 1996c. Op. cit.

7. Association of Home Appliance Manufacturers (AHAM). 1995a. Comments on the Advance Notice of Proposed Rulemaking. DOE Docket No. EE RM-94-403, comment \#27, May 8, 1995.

8. U.S. DOE. 1996c. Op. cit.

9. U.S. DOE, Energy Information Administration. 1996. Annual Energy Outlook 1996 with Projections to 2015. Washington, D.C., DOE/EIA-0383(96), January.

10. Ibid.

11. Seattle Water, Comments on the Advance Notice of Proposed Rulemaking, DOE Docket No. EE RM-94-403, comment \#29, May 8, 1995.

12. U.S. Office of the Federal Register. 1994. Op. cit.

13. Ibid.

14. AHAM. 1995a. Op. cit.

15. Ibid. 
16. AHAM. 1995b. Comments on the Advance Notice of Proposed Rulemaking. DOE Docket No. EE RM-94-403, comment \#37, June 27, 1995.

17. Ibid.

18. AHAM. 1995a. Op. cit.

19. U.S. DOE. 1996c. Op. cit.

20. Ibid. 


\section{APPENDIX A. DISAGGREGATED MANUFACTURER COST DATA}

Table A.1 shows the manufacturer costs for standard clothes washers by design option. The cost data provided by AHAM are disaggregated into variable and fixed costs. The AHAM variable cost data were supplied as per unit costs and were disaggregated into the following three categories: material/parts, labor, and shipping. The AHAM fixed cost data, not supplied on a per unit basis ${ }^{1}$, were disaggregated into the following three categories: tooling, capital costs, and other. AHAM also provided a total per unit incremental manufacturer cost for each design option.

The columns labeled "Total Variable" and "Total Fixed" in Table A.1 were derived by LBNL and represent the per unit cost for each design option. The total per unit fixed cost was determined by subtracting the total per unit variable cost from the total incremental manufacturer cost.

\footnotetext{
${ }^{1}$ This was due to AHAM's need to keep the data confidential and also from complications arising from how the data was collected.
} 
Table A.1 Disaggregated Cost of Efficiency Improvements for Standard Clothes Washers

\begin{tabular}{|c|c|c|c|c|c|c|c|c|c|c|c|}
\hline \multirow{3}{*}{$\begin{array}{c}\text { Design } \\
\text { No. }\end{array}$} & \multirow[t]{3}{*}{ Design Option } & \multirow{2}{*}{\multicolumn{4}{|c|}{$\begin{array}{c}\text { Variable Costs } \\
\text { Costs per Unit }\end{array}$}} & \multicolumn{4}{|c|}{ Fixed Costs ${ }^{1}$} & \multirow{3}{*}{$\begin{array}{c}\text { Increm. } \\
\text { per Unit } \\
\text { Mfg. } \\
\text { Costs } \\
1994 \$\end{array}$} & \multirow{3}{*}{$\begin{array}{l}\text { Total } \\
\text { Mfg. } \\
\text { Cost } \\
1994 \$\end{array}$} \\
\hline & & & & & & \multicolumn{3}{|c|}{ Costs (in Thousands) } & \multirow{2}{*}{$\begin{array}{c}\text { Per Unit } \\
\text { Total } \\
\text { Fixed }^{4} \\
1994 \$\end{array}$} & & \\
\hline & & $\begin{array}{c}\text { Material/Parts } \\
1994 \$ \\
\end{array}$ & $\begin{array}{l}\text { Labor } \\
1994 \$\end{array}$ & $\begin{array}{c}\text { Shipping } \\
1994 \$\end{array}$ & $\begin{array}{c}\text { Total } \\
\text { Variable } \\
1994 \$\end{array}$ & $\begin{array}{c}\text { Tooling } \\
1994 \$\end{array}$ & $\begin{array}{c}\text { Capital } \\
\text { Costs }^{2} \\
1994 \$\end{array}$ & $\begin{array}{l}\text { Other }^{3} \\
1994 \$\end{array}$ & & & \\
\hline 0 & Baseline (Vert. Axis) & & & & & & & & & & 225 \\
\hline $1 \mathrm{a}$ & $\mathrm{RMC}=50 \%$ & 4.50 & 0.31 & 0.00 & 4.81 & 35843 & 14950 & 2474 & 4.79 & 9.60 & 235 \\
\hline $2 \mathrm{a}$ & $1 \mathrm{a}+$ Auto Fill, TCMV & 34.93 & 1.49 & 0.00 & 36.42 & 69009 & 27745 & 14581 & 3.36 & 39.78 & 275 \\
\hline $3 a$ & 1a + Improved Fill Control & 10.98 & 0.55 & 0.00 & 11.53 & 139 & 0 & 124 & 0.05 & 11.58 & 246 \\
\hline $4 a$ & $1 \mathrm{a}+\mathrm{RMC}=40 \%$ & 7.82 & 0.01 & 0.00 & 7.83 & 41437 & 17618 & 3658 & 0.69 & 8.52 & 243 \\
\hline $5 \mathrm{a}$ & $4 \mathrm{a}+$ Auto Fill, TCMV & 35.28 & 1.49 & 0.00 & 36.77 & 75170 & 30744 & 15824 & 3.44 & 40.21 & 284 \\
\hline $6 a$ & $4 a+$ Improved Fill Control & 10.98 & 0.55 & 0.00 & 11.53 & 139 & 0 & 124 & 0.05 & 11.58 & 255 \\
\hline $1 \mathrm{~b}$ & Horizontal Axis Design & 67.98 & 8.24 & 0.56 & 76.78 & 86852 & 125690 & 15717 & 24.79 & 101.57 & 327 \\
\hline $2 b$ & $1 b+$ Auto Fill & 30.12 & 1.24 & 0.00 & 31.36 & 97957 & 143847 & 17038 & 2.79 & 34.15 & 361 \\
\hline $3 b$ & $1 \mathrm{~b}+50 \% \mathrm{RMC}$ & 7.70 & 0.17 & 0.06 & 7.93 & 97089 & 143588 & 16626 & 0.73 & 8.66 & 336 \\
\hline $4 \mathrm{~b}$ & $3 b+\mathrm{TCMV}$ & 7.70 & 0.33 & 0.00 & 8.03 & & & & 0.13 & 8.16 & 344 \\
\hline $5 \mathrm{~b}$ & $4 b+$ Auto Fill & 27.23 & 0.85 & 0.00 & 28.08 & & & & 3.54 & 31.62 & 375 \\
\hline $6 b$ & $3 b+40 \%$ RMC & 6.90 & 0.00 & 0.00 & 6.90 & 103056 & 146564 & 19619 & 0.59 & 7.49 & 343 \\
\hline $7 \mathrm{~b}$ & $6 \mathrm{~b}+\mathrm{TCMV}$ & 7.70 & 0.33 & 0.00 & 8.03 & & & & 0.13 & 8.16 & 351 \\
\hline $8 \mathrm{~b}$ & $7 b+$ Auto Fill & 27.58 & 1.15 & 0.00 & 28.73 & & & & 3.32 & 32.05 & 383 \\
\hline $1 \mathrm{c}$ & Horizontal Axis Design & 67.98 & 8.24 & 0.56 & 76.78 & 86852 & 125690 & 15717 & 24.79 & 101.57 & 327 \\
\hline $2 \mathrm{c}$ & $1 \mathrm{c}+$ Horz. Axis w/recirc. & 3.28 & 0.00 & 0.00 & 3.28 & 95728 & 134844 & 21727 & 0.00 & 3.28 & 330 \\
\hline $3 \mathrm{c}$ & $2 \mathrm{c}+50 \% \mathrm{RMC}$ & 7.70 & 0.17 & 0.06 & 7.93 & 97089 & 143588 & 16626 & 0.73 & 8.66 & 339 \\
\hline $4 \mathrm{c}$ & $3 \mathrm{c}+40 \% \mathrm{RMC}$ & 6.90 & 0.00 & 0.00 & 6.90 & 103056 & 146564 & 19619 & 0.59 & 7.49 & 346 \\
\hline $1 \mathrm{~d}$ & $0+$ Tighter Tub Tolerance & 4.61 & 0.22 & 0.00 & 4.83 & 15239 & 17137 & 836 & 2.26 & 7.09 & 232 \\
\hline $2 d$ & 1d + Improved Fill Control & 10.98 & 0.55 & 0.00 & 11.53 & 139 & 0 & 124 & 0.05 & 11.58 & 244 \\
\hline $3 d$ & $2 \mathrm{~d}+\mathrm{TCMV}$ & 7.70 & 0.33 & 0.00 & 8.03 & & & & 0.13 & 8.16 & 252 \\
\hline $4 d$ & $1 \mathrm{~d}+\mathrm{TCMV}$ & 7.70 & 0.33 & 0.00 & 8.03 & & & & 0.13 & 8.16 & 241 \\
\hline $1 \mathrm{e}$ & 0+Increase Motor Efficiency & 8.78 & 0.07 & 0.00 & 8.85 & 3043 & 2678 & 1373 & 0.66 & 9.51 & 235 \\
\hline $2 \mathrm{e}$ & 0+Direct Drive Motor & 68.87 & 0.74 & 0.00 & 69.61 & 8617 & 8528 & 4353 & 1.27 & 70.88 & 296 \\
\hline $3 \mathrm{e}$ & 0+Advanced Controls & 54.98 & 1.24 & 0.00 & 56.22 & 45668 & 15131 & 16068 & 4.53 & 60.75 & 286 \\
\hline $4 \mathrm{e}$ & $0+$ Added Insulation & 43.22 & 0.90 & 0.00 & 44.12 & 68226 & 45 & 8662 & 4.65 & 48.77 & 274 \\
\hline
\end{tabular}

${ }^{1}$ Assumes a five-year regulatory life.

${ }^{2}$ Includes production machinery, plant upgrade, and/or expansion.

${ }^{3}$ Includes R\&D, product certification, and administrative overhead.

${ }^{4}$ Fixed costs $=$ total costs - variable costs. 


\section{APPENDIX B. ADJUSTMENTS TO AHAM DATA}

Several adjustments were made to the data submitted by AHAM. These adjustments were made for the following reasons: 1) statistical variations, 2) normalizing, and 3) differences between the proposed ${ }^{1}$ AHAM and future DOE (Appendix J1) test procedures.

\section{B.1 Adjustments due to Statistical Variations}

The first step in the analysis was to review the AHAM data. In some cases not all manufacturers responded to a particular design option. Because manufacturers provided different energy and water use estimates, an energy or water use change due to a design option modification can arise simply because a different number of responses are being used to calculate the shipmentweighted average. This situation arose in the analysis of several design options and, as a result, the energy or water use had to be adjusted.

The hot water energy and total water use for all vertical axis RMC design options were set equal to the baseline values. Hot water and total water use for horizontal axis designs with $50 \%$ and $40 \% \mathrm{RMC}$ were set equal to that reported for the stand-alone horizontal axis design option. Total water use for the added insulation and direct drive motor design options were set equal to the baseline value. The mechanical energy for the added insulation design option was also set equal to the baseline value.

The clothes container volume (wash basket capacity) also varied due to statistical reasons. Where the clothes container volume differed, values were equalized and the MEF was recalculated. For the engineering analysis, clothes container volume was allowed to vary based on 1) axis orientation (vertical or horizontal) and 2) whether a recirculation design was incorporated. Thus, only three clothes container volumes were analyzed; one for vertical axis designs, another for horizontal axis designs, and one for horizontal axis with recirculation designs. Although the volume was adjusted as described above for the MEF calculation, it was assumed that all design options washed the same amount of clothes for purposes of calculating the clothes dryer energy required to dry the clothes. The issue of clothes load is discussed further in Appendix F.

\section{B.2 Adjustments due to Normalization}

In AHAM's Phase II data submittal, not all manufacturers provided data for every design option. However, a separate baseline (except for cost data) was provided for each "Phase II" design option. The energy use data for this separate baseline were based only on those responses from manufacturers who provided data for that design option. These "separate" baseline data were used to normalize the "Phase II" design option data to the five-respondent baseline used throughout the

\footnotetext{
${ }^{1}$ In this report "proposed AHAM test procedure" refers to an early version of the AHAM test procedure which was used by manufacturers to submit data.
} 
analysis. The following "Phase II" design option data were normalized: 1) hot water energy use, 2) clothes container capacity, and 3) total water use. The basic normalization equation is shown below:

$$
\text { Value }_{\text {adjusted }}=\text { Value }_{\text {unadjusted }} \cdot\left(\frac{\text { Baseline }_{5-\text { respondent }}}{\text { Baseline }_{\text {unadjusted }}}\right)
$$

$$
\begin{aligned}
& \text { where } \text { Value }_{\text {adjusted }}=\text { Design option hot water energy use, water use, or clothes } \\
& \text { container capacity normalized to 5-respondent baseline. } \\
& \text { Value }_{\text {unadjusted }}=\text { Original, Phase II, AHAM design option hot water energy use, }
\end{aligned}
$$

\section{B.3 Adjustments due to Test Procedure Changes}

All of the data submitted by AHAM that was used in the analysis was based on a proposed AHAM test procedure. Thus, adjustments had to be made to the AHAM data so that they were in accordance with the future DOE test procedure (Appendix J1). This included adjusting the hot water energy use to reflect changes in both inlet water temperature assumptions and temperature use factors (TUFs). It also included changing the dryer usage factor (DUF) from 0.83 to 0.84 . The hot water energy use adjustments are detailed below.

The future DOE test procedure assumes a value of $135^{\circ} \mathrm{F}$ for the hot water inlet temperature. The proposed AHAM's test procedure used a value of $130^{\circ} \mathrm{F}$. Thus, the hot water energy use of all the AHAM design option data was corrected by using the following equation. 


$$
H W_{\text {adjusted }}=H W_{\text {unadjusted }} \cdot\left(\frac{\Delta T_{D O E}}{\Delta T_{A H A M}}\right)
$$

$$
\begin{aligned}
& \text { where } H W_{\text {adjusted }} \quad=\text { Adjusted hot water energy use } \\
& H W_{\text {unadjusted }} \quad=\text { Hot water energy use unadjusted for changes in test procedure } \\
& \Delta T_{D O E} \quad=\text { Temperature difference between hot water inlet and cold water } \\
& \text { inlet according to proposed DOE test procedure } \\
& =135^{\circ} \mathrm{F}-60^{\circ} \mathrm{F}=75^{\circ} \mathrm{F} \\
& \Delta T_{A H A M}=\text { Temperature difference between hot water inlet and cold water } \\
& \text { inlet according to proposed AHAM test procedure } \\
& =130^{\circ} \mathrm{F}-60^{\circ} \mathrm{F}=70^{\circ} \mathrm{F}
\end{aligned}
$$

The above adjustment not only affects total energy consumption but also the cost-effectiveness of certain design options. For example, in the case of TCMV, a higher assumed inlet water temperature results in greater energy savings.

The hot water energy use for the AHAM design option data were also multiplied by a correction factor that accounted for changes in assumptions regarding TUFs. The following table details the differences in the TUFs between the proposed AHAM and the future DOE test procedures.

Table B.1 Temperature Use Factors for Proposed AHAM and Future DOE Test Procedures Temperature Use Factors

\begin{tabular}{lcc}
\cline { 2 - 3 } Wash/Rinse Selection & Proposed AHAM ${ }^{\mathbf{1}}$ Test Procedure & Future DOE Test Procedure \\
\hline Hot/Cold & $14 \%$ & $14 \%$ \\
Warm/Cold & $50 \%$ & $49 \%$ \\
Cold/Cold & $36 \%$ & $37 \%$ \\
Warm Rinse & $21-33 \%$ & $27 \%$ \\
\hline
\end{tabular}

As noted on page B-1, in this report "proposed AHAM test procedure" refers to an early version of the AHAM test procedure which was used by manufacturers to submit data.

Based on the TUFs in the future DOE test procedure, a correction factor of 0.987 was derived and used to adjust the AHAM hot water energy use data. The derivation of this correction factor is outlined below: 
First, the following assumptions were made:

1) Clothes washer is a three-selection machine, i.e., wash/rinse temperature selections are hot/cold, warm/cold, and cold/cold.

2) Baseline hot water energy use is $1.574 \mathrm{kWh} / \mathrm{cycle}$ (note that this value has already been corrected for the future DOE test procedure's hot water inlet temperature).

The following equation for the total per-cycle hot water energy consumption is then taken from the proposed AHAM test procedure [1].

$$
\begin{aligned}
& E=V_{h, A H A M} \cdot \Delta T \cdot K \\
& \text { where } E=\text { Baseline hot water energy use }(\mathrm{kWh} / \mathrm{cycle}) \\
& V_{h, A H A M}=\text { Baseline hot water use based on proposed AHAM test } \\
& \text { procedure (gallons) } \\
& \Delta T=\text { Temperature rise }\left(135^{\circ} \mathrm{F}-60^{\circ} \mathrm{F}\right)=75^{\circ} \mathrm{F} \\
& K=\text { Water specific heat }\left(\mathrm{kWh} / \mathrm{gal}^{\circ} \mathrm{F}\right)=0.00240
\end{aligned}
$$

Substituting the appropriate values in Eq. B.3 for $E, \Delta T$, and $K$, one can solve for $V_{h, A H A M}$.

$$
V_{h, A H A M}=\frac{E}{\Delta T \cdot K}=\frac{1.574 \mathrm{kWh} / \mathrm{cyc}}{75^{\circ} \mathrm{F} \cdot 0.0024 \mathrm{kWh} / \mathrm{gal}^{\circ} \mathrm{F}}=8.74 \text { gallons }
$$

The average amount of hot water used is equal to the amount used for both the hot and warm wash cycles multiplied by their respective TUFs. This is represented by the following equation.

$$
V_{h, A H A M}=\left(H_{\text {hot }} \cdot T U F_{\text {hot }}\right)+\left(H_{\text {warm }} \cdot T U F_{\text {warm }}\right)
$$

where $\quad H_{\text {hot }}=$ Hot water use for hot wash cycle (gallons) $T U F_{h o t}=$ Temperature Use Factor for hot wash cycle $H_{\text {warm }}=$ Hot water use for warm wash cycle (gallons) $T U F_{\text {warm }}=$ Temperature Use Factor for warm wash cycle 
The warm wash temperature is assumed to be the average of the cold and hot water inlet temperatures (i.e., a 50/50 mix of hot and cold water supplies). Thus, the amount of hot water used for the warm water wash is equal to half of that used for the hot water wash. This can be expressed with the following equation.

$$
H_{\text {warm }}=\frac{H_{\text {hot }}}{2}
$$

Substituting Eq. B.6 for $H_{\text {warm }}$ in Eq. B.5 we get the following equation:

$$
V_{h, A H A M}=\left(H_{h o t} \cdot T U F_{h o t}\right)+\left(\frac{H_{h o t}}{2} \cdot T U F_{\text {warm }}\right)
$$

Substituting both the proposed AHAM test procedure TUFs and the baseline hot water use in Eq. B.7, we can solve for $H_{h o t}$.

$$
H_{\text {hot }}=\frac{V_{h, A H A M}}{T U F_{\text {hot }}+\frac{T U F_{\text {warm }}}{2}}=\frac{8.74 \text { gal }}{0.14+\frac{0.50}{2}}=22.42 \text { gallons }
$$

Since $H_{\text {warm }}$ is one-half of $H_{\text {hot }}, H_{\text {warm }}$ is equal to 11.21 gallons.

Since the amount of water used in a hot wash cycle and a warm wash cycle is independent of the TUFs, the future DOE test procedure TUFs can be substituted into Eq. B.5 to determine the total hot water energy use based on the future DOE test procedure.

$$
V_{h, D O E}=(22.42 \mathrm{gal} \cdot 0.14)+(11.21 \mathrm{gal} \cdot 0.49)=8.63 \text { gallons }
$$

The correction factor $(0.987)$ is simply the ratio of the total hot water use as determined with the future DOE test procedure TUFs (8.63 gallons) divided by the total hot water use as determined with the proposed AHAM test procedure TUFs (8.74 gallons). 


\section{REFERENCES}

1. Association of Home Appliance Manufacturers (AHAM). 1995. Comments on the Advance Notice of Proposed Rulemaking. (section 4.1.1.1) DOE Docket No. EE RM-94-403, comment \#36, July 5, 1995. 


\section{APPENDIX C. RAW DATA PROVIDED BY AHAM}

Table C.1 shows cost, energy, and water use data submitted by AHAM; these data were used in the Engineering Analysis. 

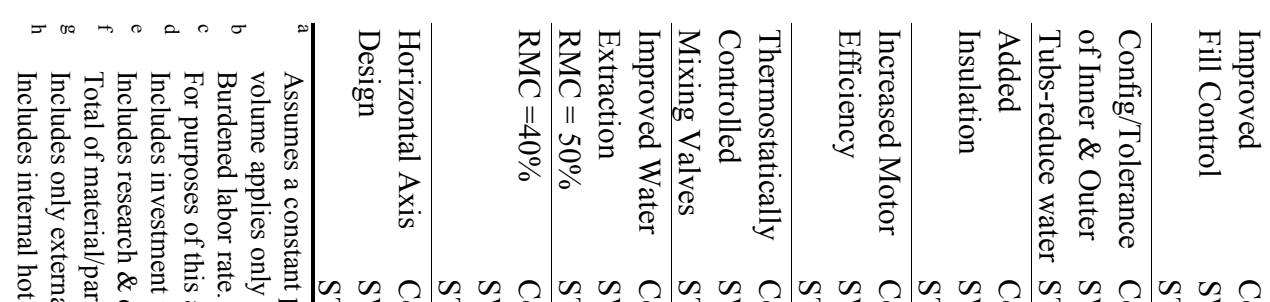

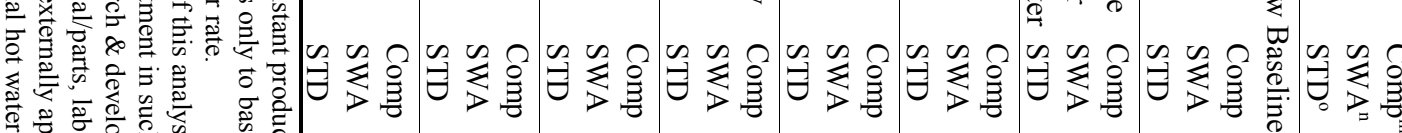

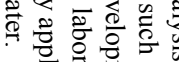

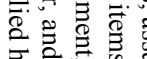

o

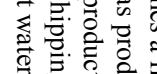

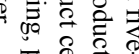

家总:

实

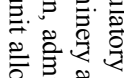

닥.

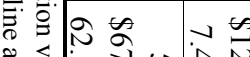

言

흘

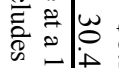

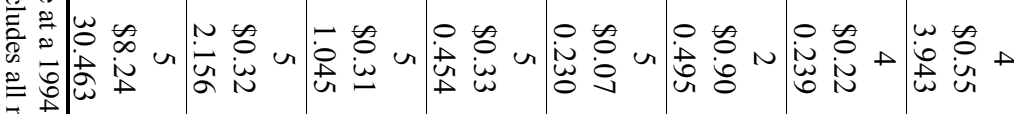

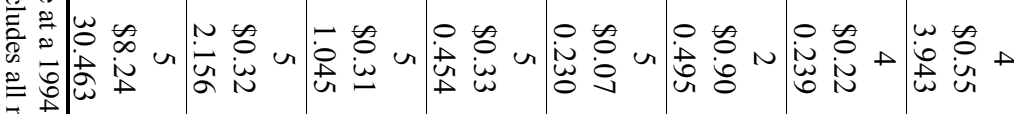

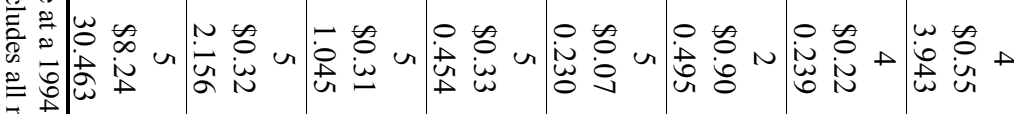

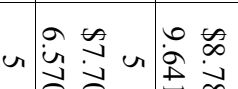

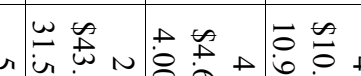

잉

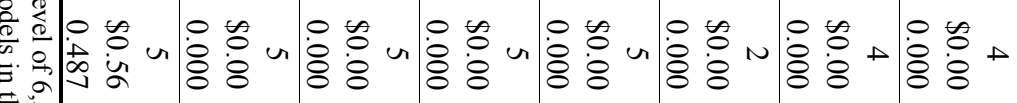

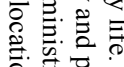

할.

:

\section{है un}

俈

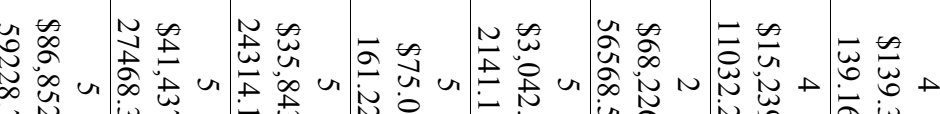

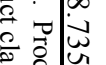

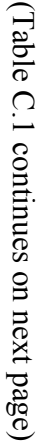

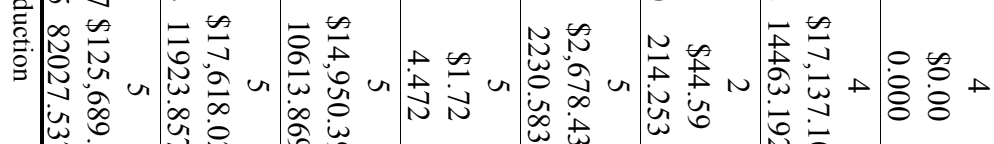

章

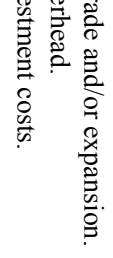

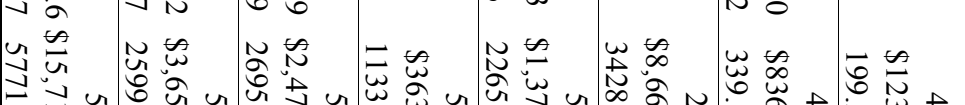

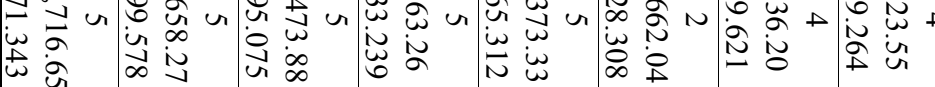

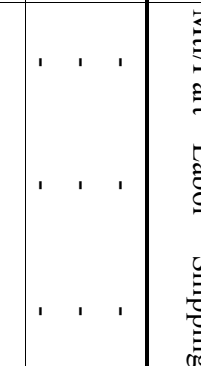

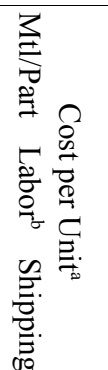

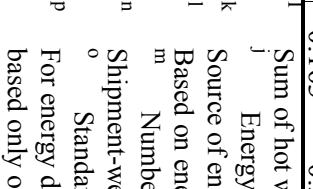

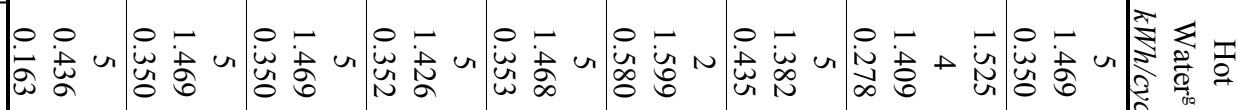

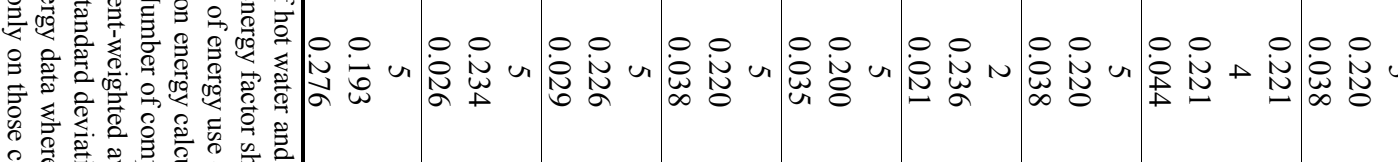

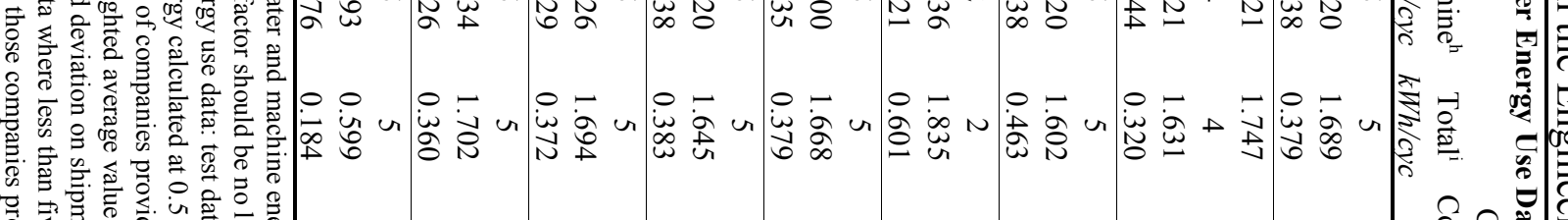

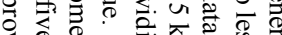

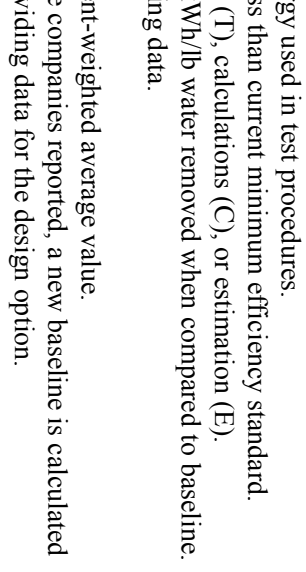

on on on on on on on on non

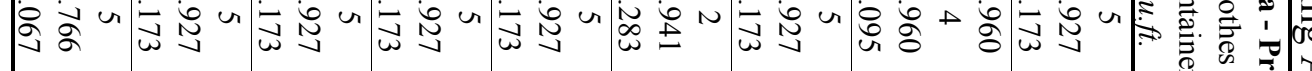

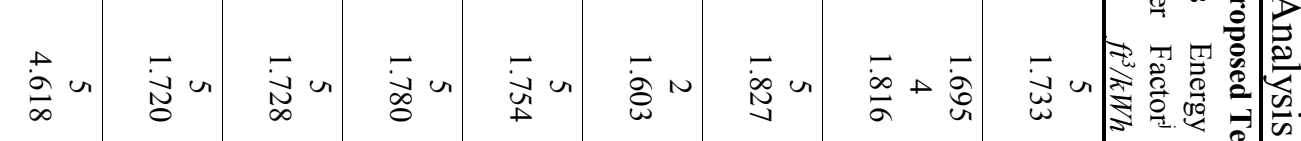

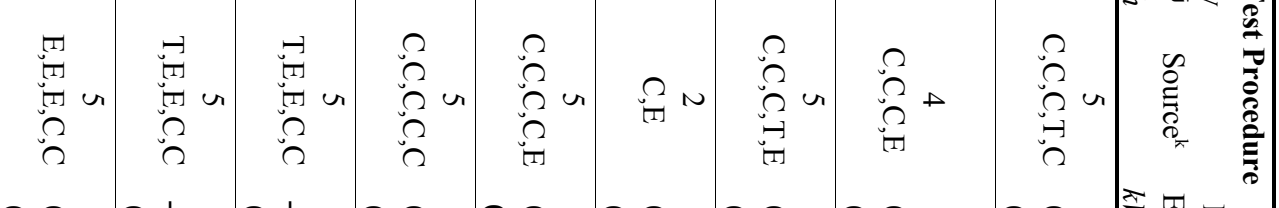

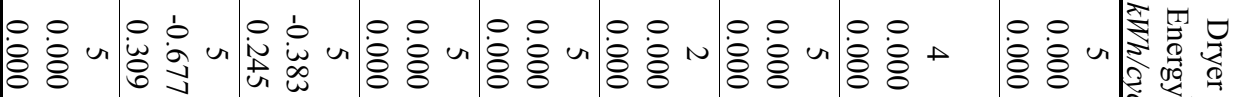

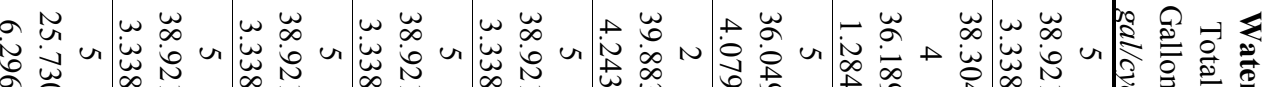

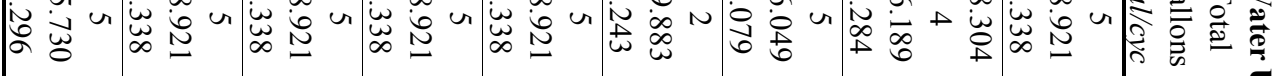

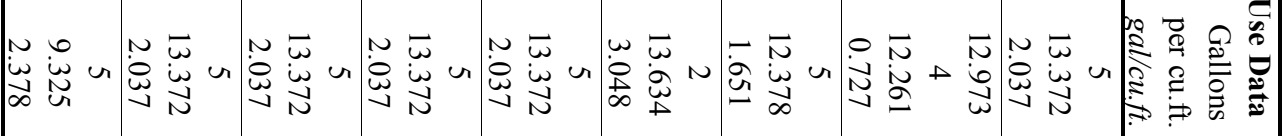




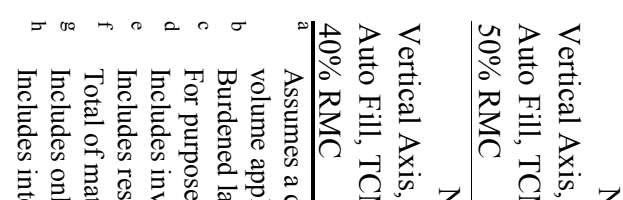

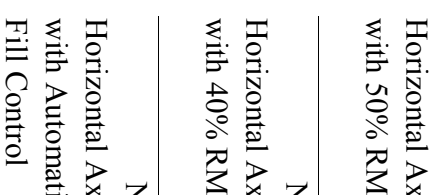

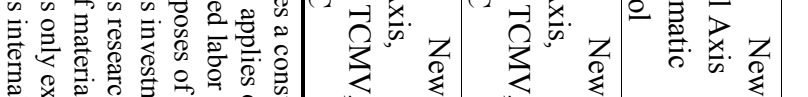

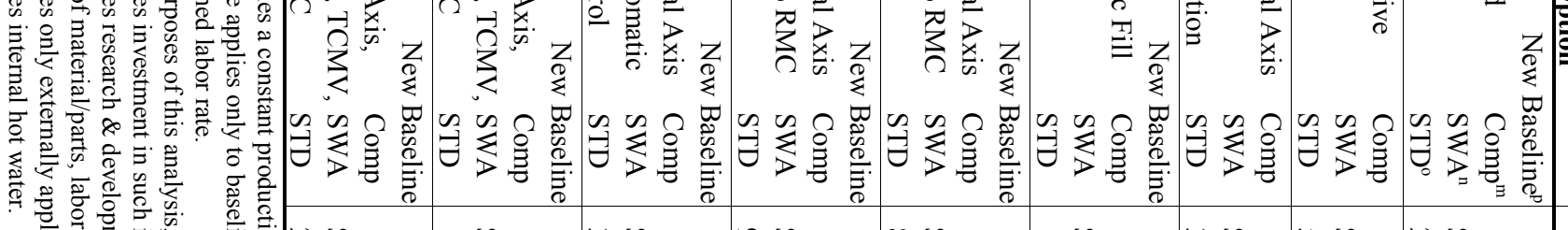

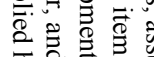

露

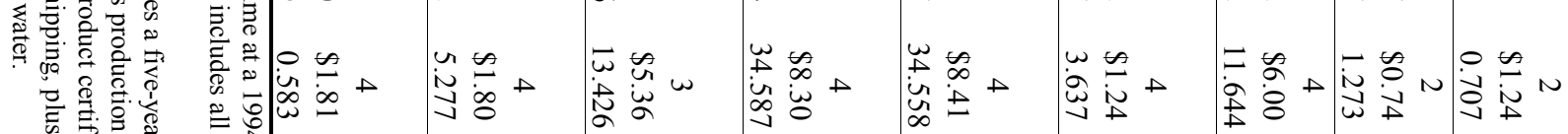

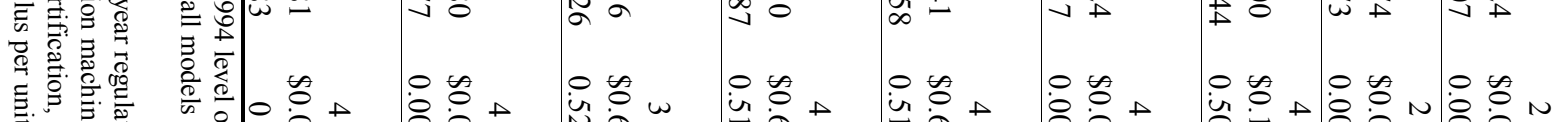

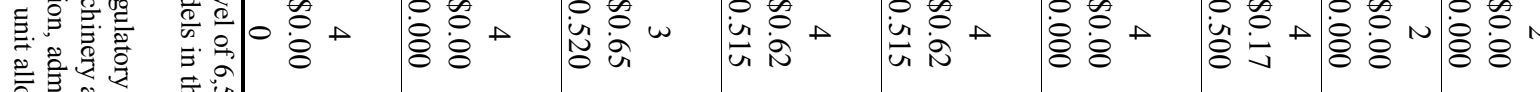

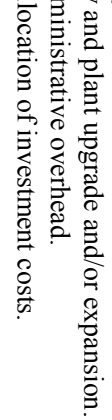

¿

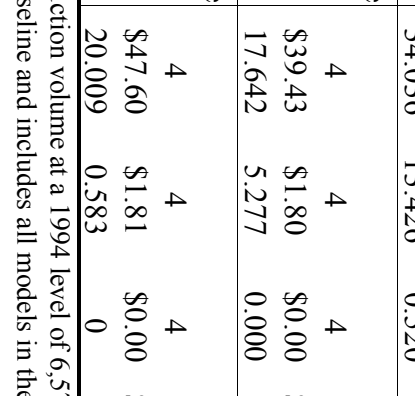

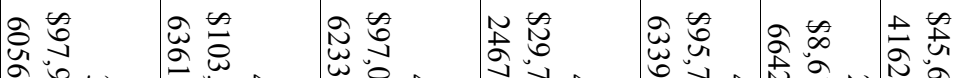

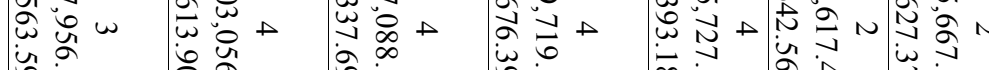

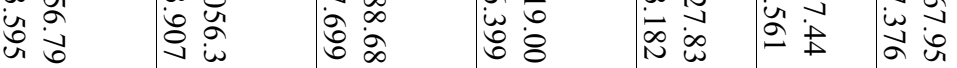

事苦

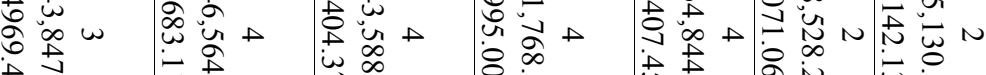

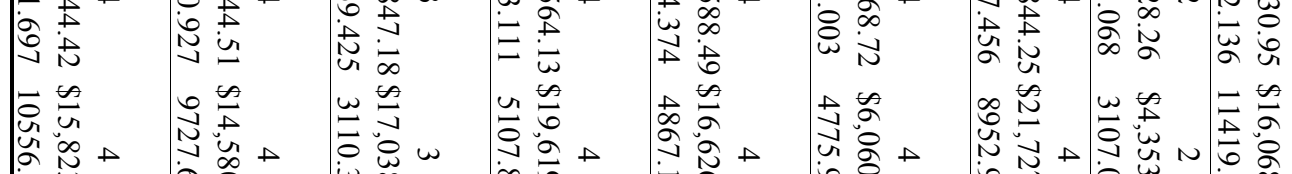

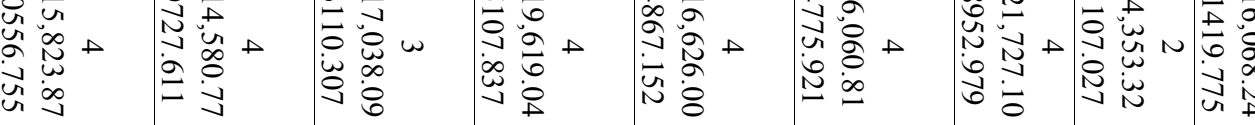

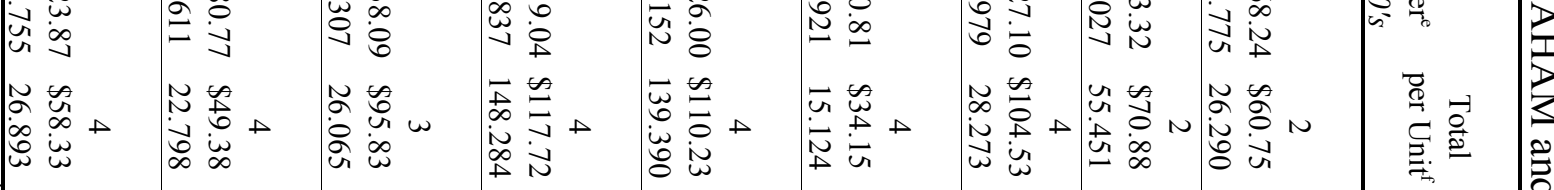

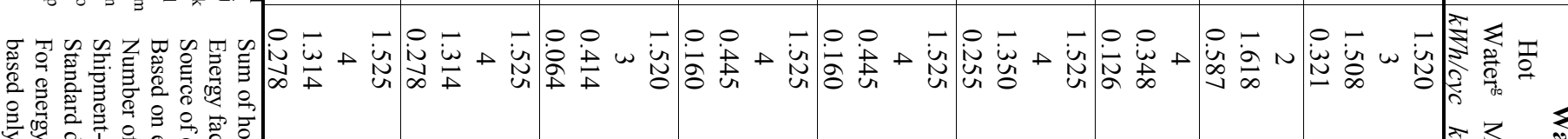

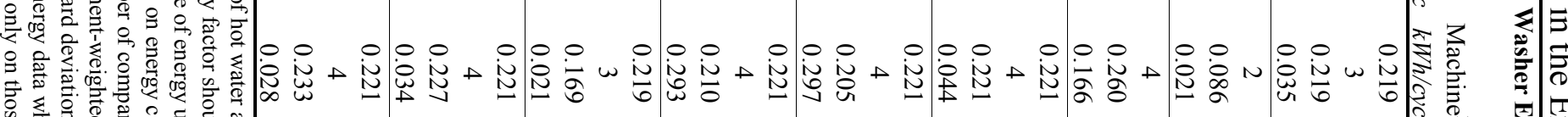

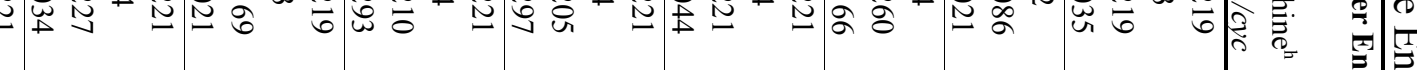

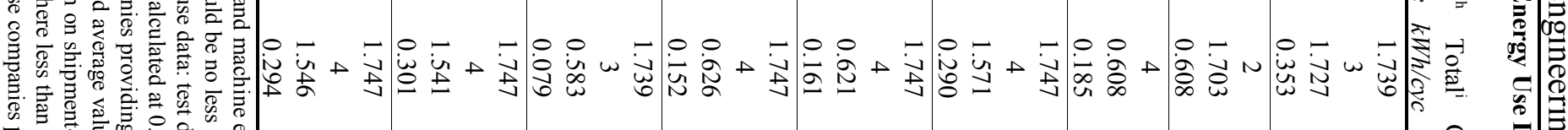

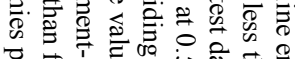

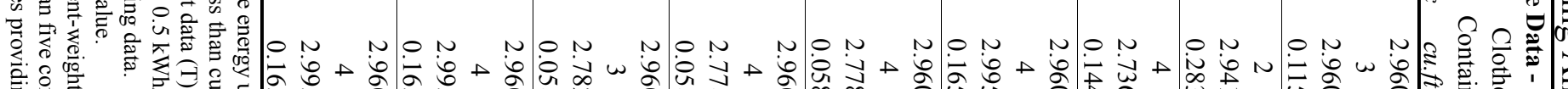

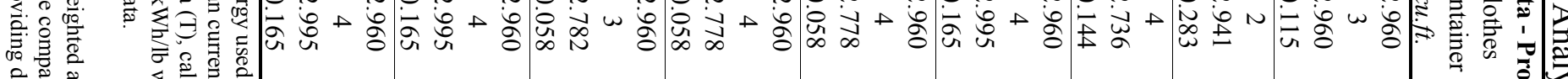

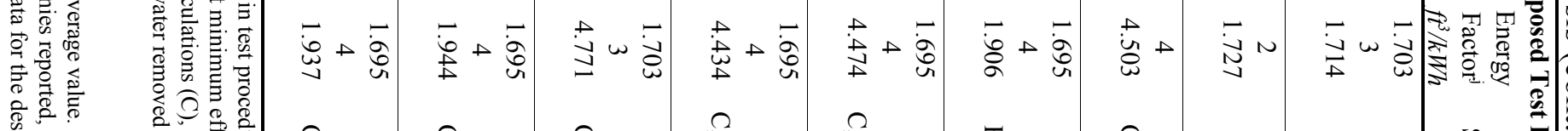

䆓:

항. 율

㱐:

贾高

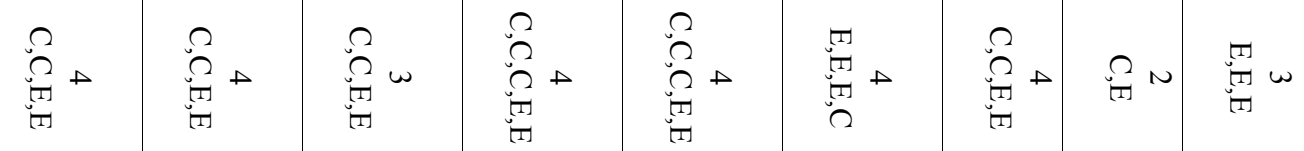

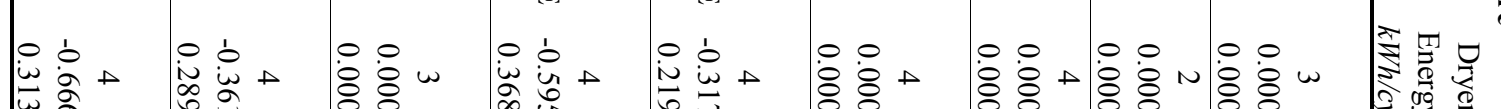

ज. $\quad$ के

承

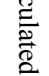

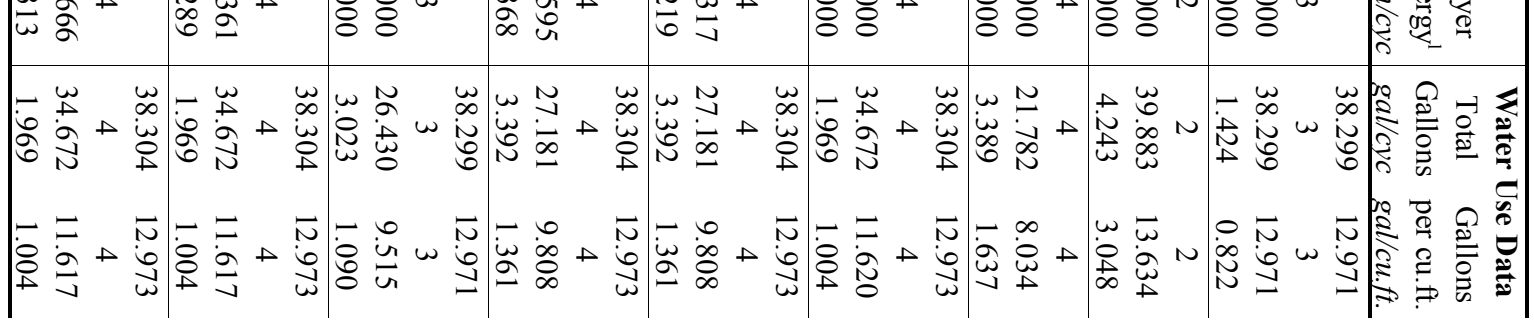


Table C. 2 provides data supplied by AHAM showing confidence levels on the design options listed in Table C.1. For each design option, the confidence levels provided in Table C.2 indicate how confident manufacturers are in 1) the accuracy of their cost and investment data and 2) their success at mass-producing and marketing a clothes washer with the prospective design option. Confidence levels are expressed as percentages with a higher value indicating increased confidence. Also included in Table C.2 are limiting performance factors for incorporating the design options in clothes washer designs.

Table C.2 AHAM Confidence Level and Limiting Performance Factor Data

\begin{tabular}{|c|c|c|c|c|c|}
\hline Design Option & & $\begin{array}{c}\text { Cost and } \\
\text { Investment Data }\end{array}$ & $\begin{array}{c}\text { Confidence Level } \\
\text { Mass Production } \\
\text { Success } \\
\end{array}$ & $\begin{array}{l}\text { Marketing } \\
\text { Success }\end{array}$ & $\begin{array}{c}\text { Limiting } \\
\text { Performance } \\
\text { Factor }^{\mathrm{a}} \\
\end{array}$ \\
\hline Improved Fill & Comp $^{b}$ & 4 & 4 & 4 & 4 \\
\hline Control & $\begin{array}{l}\mathrm{SWA}^{\mathrm{c}} \\
\mathrm{STD}^{\mathrm{d}}\end{array}$ & $\begin{array}{c}66.781 \% \\
0.150 \\
\end{array}$ & $\begin{array}{c}79.579 \% \\
0.075 \\
\end{array}$ & $\begin{array}{c}47.637 \% \\
0.210 \\
\end{array}$ & $\begin{array}{c}1,1,4,4,4,7,8,12 \\
15,15,16,17\end{array}$ \\
\hline $\begin{array}{l}\text { Config/Tolerance } \\
\text { of Inner \& Outer } \\
\text { Tubs-Reduce }\end{array}$ & $\begin{array}{l}\text { Comp }^{\mathrm{b}} \\
\text { SWA }^{\mathrm{c}} \\
\text { STD }^{\mathrm{d}}\end{array}$ & $\begin{array}{c}4 \\
69.340 \% \\
0.075 \\
\end{array}$ & $\begin{array}{c}4 \\
54.540 \% \\
0.217 \\
\end{array}$ & $\begin{array}{c}4 \\
87.030 \% \\
0.075 \\
\end{array}$ & $\begin{array}{c}5 \\
1,2,4,5,5,5,7,10,10 \\
11,11,13,14,15,16\end{array}$ \\
\hline $\begin{array}{l}\text { Added } \\
\text { Insulation }\end{array}$ & $\begin{array}{l}\text { Comp }^{\mathrm{b}} \\
\text { SWA }^{\mathrm{c}} \\
\text { STD }^{\mathrm{d}}\end{array}$ & $\begin{array}{c}2 \\
53.680 \% \\
0.177 \\
\end{array}$ & $\begin{array}{c}2 \\
37.360 \% \\
0.354 \\
\end{array}$ & $\begin{array}{c}2 \\
39.570 \% \\
0.460 \\
\end{array}$ & $\begin{array}{c}2 \\
0,0,2,6,7,9,14\end{array}$ \\
\hline $\begin{array}{l}\text { Increased Motor } \\
\text { Efficiency }\end{array}$ & $\begin{array}{l}\text { Comp }^{b} \\
\text { SWA }^{\mathrm{c}} \\
\text { STD }^{\mathrm{d}}\end{array}$ & $\begin{array}{c}5 \\
77.680 \% \\
0.110 \\
\end{array}$ & $\begin{array}{c}5 \\
91.900 \% \\
0.110 \\
\end{array}$ & $\begin{array}{c}5 \\
75.690 \% \\
0.259 \\
\end{array}$ & $\begin{array}{c}5 \\
0,2,2,2,5,6,6,10,12\end{array}$ \\
\hline $\begin{array}{l}\text { Thermostatically } \\
\text { Controlled } \\
\text { Mixing Valves }\end{array}$ & $\begin{array}{l}\text { Comp }^{\mathrm{b}} \\
\mathrm{SWA}^{\mathrm{c}} \\
\mathrm{STD}^{\mathrm{d}}\end{array}$ & $\begin{array}{c}5 \\
62.590 \% \\
0.084 \\
\end{array}$ & $\begin{array}{c}5 \\
97.840 \% \\
0.055 \\
\end{array}$ & $\begin{array}{c}5 \\
56.430 \% \\
0.246 \\
\end{array}$ & $\begin{array}{c}5 \\
1,1,1,7,13\end{array}$ \\
\hline $\begin{array}{l}\text { Improved Water } \\
\text { Extraction } \\
\mathrm{RMC}=50 \%\end{array}$ & $\begin{array}{l}\text { Comp }^{b} \\
\text { SWA }^{\mathrm{c}} \\
\text { STD }^{\mathrm{d}}\end{array}$ & $\begin{array}{c}5 \\
71.170 \% \\
0.061\end{array}$ & $\begin{array}{c}5 \\
78.840 \% \\
0.124\end{array}$ & $\begin{array}{c}5 \\
76.860 \% \\
0.190\end{array}$ & $\begin{array}{c}5 \\
3,5,5,5,9,10,10,10,15\end{array}$ \\
\hline $\mathrm{RMC}=40 \%$ & $\begin{array}{l}\text { Comp }^{\mathrm{b}} \\
\text { SWA }^{\mathrm{c}} \\
\text { STD }^{\mathrm{d}}\end{array}$ & $\begin{array}{c}5 \\
48.280 \% \\
0.045 \\
\end{array}$ & $\begin{array}{c}5 \\
61.260 \% \\
0.199 \\
\end{array}$ & $\begin{array}{c}5 \\
64.590 \% \\
0.135 \\
\end{array}$ & $\begin{array}{c}5 \\
3,3,3,5,5,5,10,10,10 \\
12,14,15\end{array}$ \\
\hline $\begin{array}{l}\text { Horizontal Axis } \\
\text { Design }\end{array}$ & $\begin{array}{l}\text { Comp }^{\mathrm{b}} \\
\text { SWA }^{\mathrm{c}} \\
\text { STD }^{\mathrm{d}}\end{array}$ & $\begin{array}{c}5 \\
62.438 \% \\
0.152\end{array}$ & $\begin{array}{c}5 \\
91.899 \% \\
0.292\end{array}$ & $\begin{array}{c}5 \\
67.942 \% \\
0.313\end{array}$ & $\begin{array}{c}5 \\
1,1,2,5,6,7,7,8,8,9,9,9,10 \\
10,11,14,16,16,16,17,17\end{array}$ \\
\hline $\begin{array}{l}\text { Factors that are } \\
\text { 1. Soil Removal } \\
\text { 2. Physical Size } \\
\text { 3. Wrinkling } \\
\text { 4. Gentleness of } \\
\text { 5. Noise } \\
\text { 6. Servicing/Ins }\end{array}$ & Alation & $\begin{array}{r}\text { licate multiple nu } \\
7 . \\
8 . \\
9 . \\
10 . \\
11 . \\
12 .\end{array}$ & $\begin{array}{l}\text { mber of companies } \\
\text { Consumer Interface } \\
\text { Cangling } \\
\text { Cycle Time } \\
\text { Vibration } \\
\text { Sand Removal } \\
\text { Safety }\end{array}$ & $\begin{array}{l}\text { ng the factor } \\
\text { sonomics) }\end{array}$ & $\begin{array}{l}\text { concern. } \\
\text { 13. Whiteness Retention } \\
\text { 14. Capacity } \\
\text { 15. Wear } \\
\text { 16. Rinsing } \\
\text { 17. Suds Sensitivity }\end{array}$ \\
\hline $\begin{array}{ll}\text { b } & \text { Number of com } \\
\text { c } & \text { Shipment-weigh } \\
\text { d } & \text { Standard deviat }\end{array}$ & iies pro & $\begin{array}{l}\text { ding data. } \\
\text { value. }\end{array}$ & age value. & & \\
\hline
\end{tabular}

(Table C.2 continues on next page) 
Table C.2 AHAM Confidence Level and Limiting Performance Factor Data (cont.)

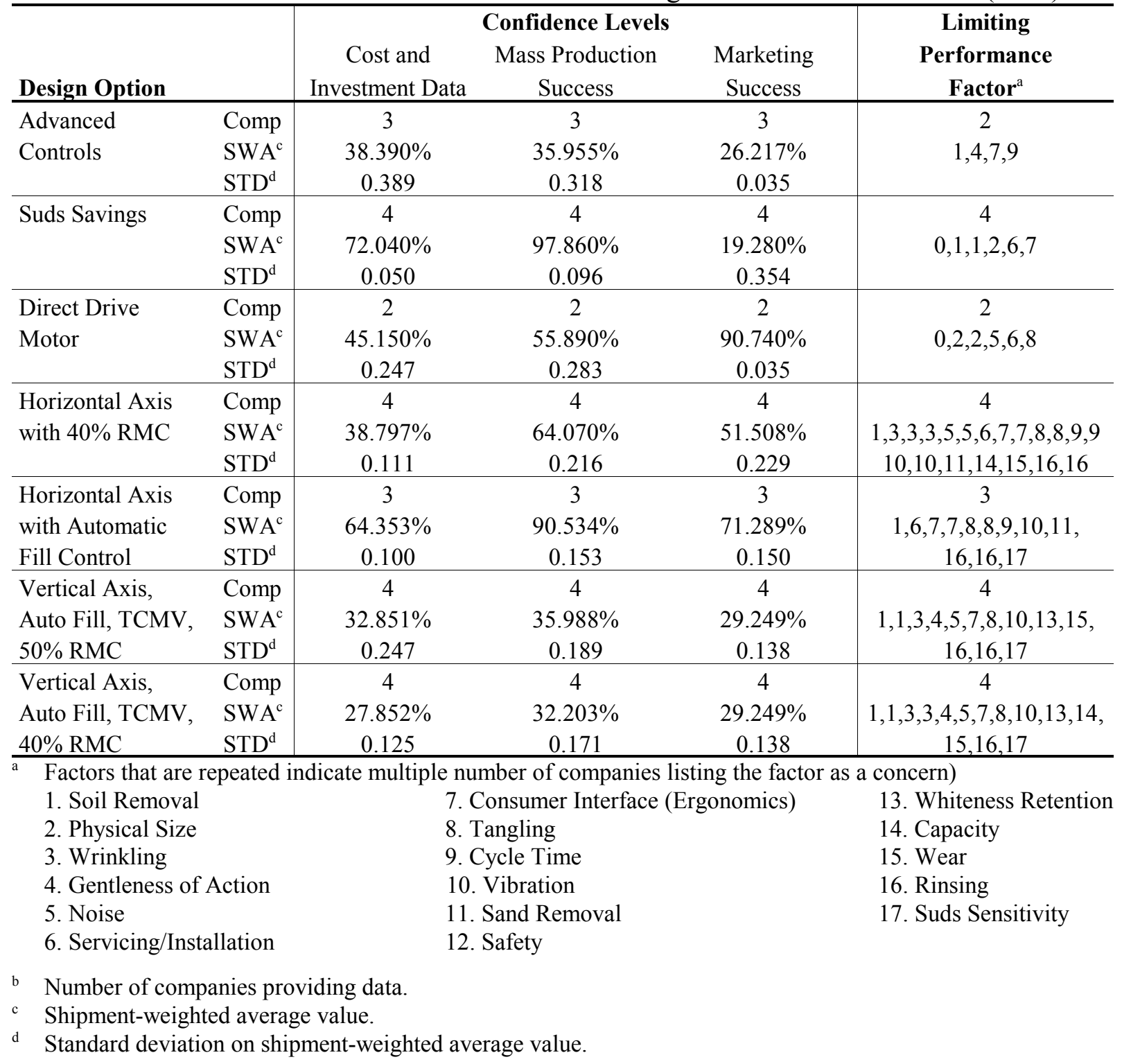




\section{APPENDIX D. DRYER EFFICIENCY FUEL CORRECTION DERIVATION}

An adjustment to the $D_{e f}$ (the amount of energy required by a dryer to remove moisture) was required for gas dryers because the value of $0.5 \mathrm{kWh} / \mathrm{lb}$ used in the future DOE test procedure (Appendix J1) was determined based on the use of an electric dryer. A correction factor was derived from data submitted by AHAM as part of their dryer data submittal [1]. The data is summarized in the following table.

Table D.1 Dryer Energy at 70\% Initial Moisture Content

\begin{tabular}{lrrr}
\hline Clothes Dryer Type & $\begin{array}{r}\text { Gas Energy } \\
k W h / c y c l e\end{array}$ & $\begin{array}{r}\text { Electric Energy } \\
k W h / c y c l e\end{array}$ & $\begin{array}{r}\text { Total Energy } \\
k W h / c y c l e\end{array}$ \\
\hline Electric & & 2.210 & 2.210 \\
Gas & 2.379 & 0.102 & 2.481 \\
\hline
\end{tabular}

A simple ratio of the total drying energy can then be used as a correction factor to the $D_{e f}$.

$$
G C F=\frac{\text { Gas Dryer Total Energy }}{\text { Electric Dryer Total Energy }}=\frac{2.481}{2.210}=1.12
$$

where $G C F=$ Gas Correction Factor

Thus, the energy required to remove moisture in a gas clothes dryer is represented by the following equation.

$$
D_{e f, g a s}=D_{e f} \cdot G C F
$$

where $\quad D_{e f, g a s}=$ gas dryer energy required to remove moisture $(\mathrm{kWh} / \mathrm{lb})$

$D_{e f}=$ electric dryer energy required to remove moisture $(\mathrm{kWh} / \mathrm{lb})$

To simplify the calculation of the energy expense of drying clothes in a gas dryer, all the energy used by a gas dryer is assumed to be priced at the cost of gas (including the small amount of electricity that is used). 


\section{REFERENCES}

1. Association of Home Appliance Manufacturers (AHAM). 1995. Comments on the Advance Notice of Proposed Rulemaking. DOE Docket No. EE RM-94-403, comment \#37, June 27, 1995. 


\section{APPENDIX E. CALCULATIONS FOR IMPROVED WATER EXTRACTION DESIGN OPTION}

In calculating the benefits of improved water extraction, several parameters were taken into consideration. These include 1) the amount of energy saved in the clothes dryer for every extra pound of moisture removed in the washer, 2) the fraction of clothes dryer loads per washer load (some clothes are line-dried), 3) the average load size, 4) the moisture content of the clothes before entering the clothes dryer, and 5) the fraction of time the lower RMC option is used. These are described in greater detail below.

The dryer energy $\left(D_{e}\right)$ is defined as the amount of energy needed to completely dry the test load in a clothes dryer after the washer final spin cycle. The amount of energy needed to dry clothes after they are removed from the clothes washer depends on how much moisture is retained after the final spin. The remaining moisture is specified as a percentage of the "bone dry" weight of a standard test load. For this analysis, a baseline RMC of $62 \%$ after the final spin cycle was assumed. This is based on data AHAM submitted on shipment-weighted averages for a baseline washer. A $62 \%$ RMC means that the weight of a wet test load weighs $62 \%$ more than a bone dry test load (1.62 $\times$ dry test load). After being dried in a clothes dryer, the test load is assumed to have a residual RMC of $4 \%$.

The future DOE test procedure (Appendix J1) provides a table that specifies the maximum clothes load for a given size clothes washer. For a 2.9 to $3.0 \mathrm{ft}^{3}$ washer, the maximum load is 12.1 lbs. The average load to maximum load fraction, 0.52 , was derived from Procter $\&$ Gamble data and made part of the proposed and future DOE test procedures. The dryer energy is sometimes also referred to as moisture removal energy. The equation describing the dryer energy is given below.

where:

$$
D_{e}=L A F \cdot(\text { Max. Load }) \cdot\left(R M C-R M C_{4 \%}\right) \cdot D_{e f} \cdot D U F
$$

LAF $\quad=$ Load Adjustment Factor $=0.52$

Max. Load $=$ Maximum clothes load $=12.1 \mathrm{lbs} /$ cycle

RMC = Remaining Moisture Content after final spin cycle, (expressed as a fraction)

$R M C_{4 \%} \quad=$ Remaining Moisture Content with a 4\% residual, (expressed as a fraction)

$D_{e f} \quad=0.5 \mathrm{kWh} / \mathrm{lb}$ of moisture (nominal energy required for clothes dryer to remove moisture)

DUF $=$ Dryer Usage Factor $=0.84$. DUF is the ratio of dryer cycles to clothes washer cycles per year.

Since it is not expected that consumers would use higher spin speed or other options to 
reduce the remaining moisture content $100 \%$ of the time, the future DOE test procedure (Appendix J1) assumes that consumers will use the lower remaining moisture content option 75\% of the time and the baseline case of $62 \%$ remaining moisture content the remaining $25 \%$ of the time. The adjusted dryer energy is shown in the equation below.

$$
D_{e, \text { adjusted }}=0.75 \cdot D_{e, \text { reduced }}+0.25 \cdot D_{e, 62 \%}
$$

where:

$$
\begin{aligned}
D_{e, \text { reduced }}= & \text { the dryer energy required with using a improved moisture } \\
& \text { extraction design option (lower RMC option). } \\
D_{e, 62 \%}= & \text { the dryer energy required with the baseline RMC of } 62 \% .
\end{aligned}
$$




\section{APPENDIX F. CLOTHES CONTAINER CAPACITY}

Although the proposed DOE test procedure specifies different amounts of cloth test loads varying with clothes container volume, for purposes of this analysis the amount of clothes washed per cycle was assumed to be the same for all design options. Consideration was given to adjusting the energy use values to account for the slightly smaller horizontal axis clothes container capacity, and therefore, smaller test load size in accordance with the future DOE test procedure (Appendix J1). However, because of disagreements over clothes container capacity measurement and clothes loading in vertical and horizontal axis washers, adjustments to the horizontal axis clothes container capacity were not made.

With regard to vertical axis washers, clothes container capacity - as measured according to the future DOE test procedure - includes volume above the water line. Some argue that including volume above the water line overstates the usable clothes container capacity. But others claim that this volume should be included since clothes above the water level will be pulled down into the water as they become wet and compacted. This of course assumes that clothes filled to this level will still receive an adequate wash. With regard to horizontal axis washers, claims have been made that for the available clothes container capacity, more clothes can be loaded into a horizontal axis washer than in a vertical axis machine while still achieving satisfactory wash performance.

Another consideration for assuming a constant load size is to allow for fair comparisons between different design options. For example, assuming a smaller clothes load for horizontal axis washers would reduce its calculated wash and drying energy. This would overstate the energy savings of horizontal axis washers relative to that of vertical axis washers. It should be noted, however, that the MEF normalizes the energy usage to the rated volume by dividing the clothes container volume by the total energy use. 